\title{
A CONTRATAÇÃO DE LICENCIAMENTO DE SOFTWARE NA ADMINISTRAÇÃO PÚBLICA / THE HIRING A SOFTWARE LICENSING IN PUBLIC ADMINISTRATION
}

\author{
Raphael Lobato Collet Janny Teixeira. ${ }^{1}$
}

\begin{abstract}
RESUMO
O presente artigo trata da contratação de licenciamento de uso de softwares no âmbito da Administração Pública. É feita uma análise das vantagens na padronização da contratação de softwares. Também é analisada a necessidade de realização de um prévio estudo técnico, para verificar, dentre as soluções existentes no mercado, quais atendem satisfatoriamente a demanda da Administração Pública. Aborda-se a legitimidade da contratação com fundamento na "padronização pelo uso". Por outro lado, é constatado que a padronização não pode causar um engessamento da Administração Pública na contratação de programas de computador. É vital a revisão das vantagens econômicas, técnicas e corporativas da padronização, mormente perante a rápida e ininterrupta inovação em TI, afora o uso de software livre na Administração Pública. Por fim, é enfrentada a questão da legitimidade do titular de programa de computador para indicação de representante comercial exclusivo para a comercialização ou prestação de serviços relacionados ao software.
\end{abstract}

Palavras chave: Licenciamento de uso de software. Administração pública. Padronização de contratação. Software livre.

\begin{abstract}
This article discusses the hiring of licensing software use in Public Administration . An analysis of the advantages of the standardization of contracting of software is made. Also analyzes the need to conduct a preliminary technical study to verify, among the existing solutions in the market, which is satisfactorily to attend the demands of the Public Administration. Addresses the legitimacy of hiring on the basis of " standardization by use". On the other hand, it is found that the standardization can do not cause inflexibility of Public Administration in hiring computer programs. It is vital the review of economic, technical and corporate advantages of standardization, especially because of the rapid and continuous innovation in information technology, apart from the use of free software in Public Administration. Finally, we faced the question of the legitimacy of the owner of the computer program to indicate exclusive sales representative for marketing or provision of services related to the software program.
\end{abstract}

\footnotetext{
${ }^{1}$ Advogado do setor especializado em TI, TCOM e direito digital da Petrobras. Pós graduação latu sensu em propriedade industrial pela UERJ.
}

Revista Quaestio luris, vol.04, n-01. ISSN 1516-0351 p.613-622 613 
Keywords : Licensing of software use. Public administration . Standardization of hiring. Free software.

\section{I - INTRODUÇÃO}

Para a celebração de um contrato pela Administração Pública, a regra é que seja esta antecedida de procedimento licitatório, de forma a se resguardar, precipuamente, os princípios da igualdade de participação de todos os interessados em oferecer propostas e da economicidade na obtenção do bem desejado pela Administração.

Neste sentido, encontra-se preceituado no inciso XXI do art. 37 da CF/88 que "ressalvados os casos especificados na legislação, as obras, serviços, compras e alienações serão contratados mediante processo de licitação pública que assegure igualdade de condições a todos os concorrentes, com cláusulas que estabeleçam obrigações de pagamento, mantidas as condições efetivas da proposta, nos termos da lei, o qual somente permitirá as exigências de qualificação técnica e econômica indispensáveis à garantia do cumprimento das obrigações".

No caso da contratação de bens e serviços de informática, a Administração deve seguir o preceituado no art. $45, \S 4^{\circ}$, da Lei n. 8.66693, adotando-se obrigatoriamente o tipo de licitação "técnica e preço", permitido o emprego de outro tipo de licitação nos casos indicados em decreto do Poder Executivo.

Isso não quer dizer que houve um engessamento no tipo de licitação para bens e serviços de informática. Neste sentido, ensina Marçal Justen Filho que "a licitação de tipo de técnica será aplicada sempre que a necessidade administrativa envolver alguma característica especial ou peculiar, que não possa ser satisfeita por meio dos produtos padronizados. (...) É imperioso, por tudo isso, que a adoção de licitação de técnica e preço seja voltada a selecionar efetivamente os bens e serviços que apresentem desempenho e qualidades técnicas mais significativos ${ }^{2 "}$. (Destaques nossos).

Nota-se, assim, que é juridicamente possível a contratação dos referidos bens adotando-se outros tipos de licitação, ou até diretamente, por inexigibilidade, desde que com fundamento no princípio da padronização, conforme veremos a seguir.

\section{II - DO PRINCÍPIO DA PADRONIZAÇÃO}

Licitações:

O princípio da padronização encontra-se consignado no art. 15 da Lei de

Art.15. As compras, sempre que possível, deverão:

\footnotetext{
${ }^{2}$ Comentários à Lei de Licitações e Contratos Administrativos", 9a ed. São Paulo: Dialética, 2002, p. $416 / 417$
} 
I - atender ao princípio da padronização, que imponha compatibilidade de especificações técnicas e de desempenho, observadas, quando for o caso, as condições de manutenção, assistência técnica e garantia oferecidas;

O princípio da padronização, portanto, deve ser adotado sempre que possível, tendo natureza de um dever legal. A regra é, assim, a padronização nas contratações perpetradas pela Administração.

O princípio da padronização pode levar, inclusive, a justificação de uma contratação direta por inexigibilidade de licitação. Neste sentido, já decidira o egrégio TCU - Tribunal de Contas da União:

“...a indicação de marca na especificação de produtos de informática pode ser aceita frente ao princípio da padronização previsto no art. 15, I, da Lei 8666/93, desde que a decisão administrativa que venha a identificar o produto pela sua marca seja circunstancialmente motivada e demonstre ser essa a opção, em termos técnicos e econômicos, mais vantajosa para a Administração". 3 inúmeras vantagens ${ }^{4}$.

Ademais, a contratação padronizada de licenciamento de programas traz

Do ponto de vista econômico, é vantajoso para a Administração pelo ganho em economia de escala. $\mathrm{O}$ custo médio do produto tende a ser menor com o aumento de unidades adquiridas. Além disso, economiza-se na contratação de um mesmo fornecedor para prestação de serviços de manutenção, suporte técnico, treinamento de pessoal, etc.

Do ponto de vista técnico e corporativo, a vantagem da padronização decorre da compatibilidade de especificações técnicas e de desempenho, evitando-se problemas como sistemas que não se comunicam ou que não funcionam de maneira integrada. Assim, a padronização evita a multiplicação de diferentes soluções tecnológicas para um mesmo problema em diferentes órgãos da Administração.

Por outro lado, a ausência de padronização levaria a sucessivas trocas de programas, com a conseqüente perda de investimentos feitos em aplicativos anteriormente instalados. Assim, a realização do certame em cada nova necessidade de licenciamento certamente causaria ineficiência na atividade desenvolvida pelo órgão por restar substancialmente prejudicada pelas trocas corriqueiras de programas de computador, o que demandaria, ainda, investimentos em adaptação, adequação de sistemas, treinamento de pessoal, etc.

\footnotetext{
${ }^{3}$ Acórdão no $1521 / 2003$ - Plenário

${ }^{4}$ Vale ressaltar que tratamos aqui dos softwares já desenvolvidos e disponíveis para licenciamento no mercado, e não da contratação para desenvolvimento de software, feita por encomenda.
} 
A padronização, enfim, garante a manutenção da garantia técnica de equipamentos, tratando-se, inclusive, de hipótese de dispensa de licitação, no caso da aquisição de componentes ou peças ${ }^{5}$.

\section{III - DAS HIPÓTESES DE LICITAÇÃO E DE CONTRATAÇÃO DIRETA}

Diante do exposto, e tendo o princípio da padronização como norteador da contratação de licenciamento de programas de computador, indaga-se: como saber se se trata de hipótese de licitação ou de contratação direta de um software?

\section{III.a - DA NECESSIDADE DE PRÉVIO ESTUDO TÉCNICO}

Antes de mais, entendemos ser recomendável a realização de um estudo técnico, com teste de software se possível, para verificar, dentre as soluções existentes no mercado, quais são capazes de atender satisfatoriamente à demanda da Administração, tendo em vista a funcionalidade, confiabilidade, usabilidade, eficiência, manutenibilidade e portabilidade, compatibilidade com os sistemas, etc. Assim, de forma geral, mensurar o bom funcionamento de um software envolve compará-lo com elementos como especificações, outros softwares da mesma linha, versões anteriores do mesmo produto, inferências pessoais, expectativas do cliente, normas relevantes, leis aplicáveis, dentre outros. Enquanto a especificação do software diz respeito ao processo de verificação do software, a expectativa do cliente diz respeito ao processo de validação do software ${ }^{6}$.

O referido estudo deverá possuir um questionário de natureza disjuntiva, ou seja, se o programa em questão "atende" ou "não atende", o requisito definido como necessário e imprescindível para a Administração ${ }^{7}$.

O estudo técnico poderá concluir, assim, pela necessidade de uma única ou de diversas soluções tecnológicas a serem adotadas como padrão pela Administração simultaneamente. No segundo caso, será possível a realização, desde o início, de contratação direta de cada uma das soluções tecnológicas a serem padronizadas, tendo em vista que todas elas possuem alguma peculiaridade que as tornam únicas e imprescindíveis para a

\footnotetext{
${ }^{5}$ Vide inciso XVII do art. 24 da Lei 8666/93. Neste sentido, o eminente Jessé Torres Pereira Júnior. (Comentários à Lei das Licitações e Contratações da Administração Pública. 2003. Pág. 322):"Com efeito, não haverá competição no interesse do serviço se a peça ou o componente indispensável à manutenção de um equipamento não puder ser adquirido a qualquer fornecedor que o ofereça nas condições mais vantajosas, porque o seu fabricante recusa a garantia se o equipamento receber peça ou componente diverso do original. Nessas circunstâncias, a condição mais vantajosa não é a do menor preço, mas a que vincule a responsabilidade do fabricante pelo correto funcionamento da máquina, o que, a seu turno, vincula o interesse da Administração". (Destaques nossos).

${ }^{6}$ Em www.pt.wikipedia.org/wiki/Teste de software. Página visitada em 02/1/2009.

7 Por outro lado, caso o estudo técnico tenha natureza classificatória mediante atribuição de pontuação para cada quesito, o resultado não poderá induzir a uma contratação direta, pois, neste caso, não dispensará a realização de procedimento licitatório de melhor técnica ou técnica e preço. Note-se que, neste caso, não haverá uma situação de unicidade ou inviabilidade de competição, mas de ordem de classificação por pontuação. Ora, se há uma ordem de classificação, é inafastável a exigência constitucional e legal da licitação.
} 
Administração, apesar de, em tese, todas serem destinadas para uma mesma finalidade. Isso pode ocorrer, inclusive, em situações em que não convém à Administração ficar refém de um único fornecedor ou de um único produto padronizado.

De outra forma, o estudo pode concluir que existem no mercado diversos softwares que atenderiam satisfatoriamente aos requisitos estabelecidos pela Administração sem que haja justificativa para a sua contratação simultânea. Neste caso, será necessária a realização de procedimento licitatório para garantir a competição e a seleção da proposta mais vantajosa para a Administração. Após a realização do certame, estabelecer-se-á o padrão corporativo junto à vencedora, e, com isso, as contratações sucessivas poderão ser diretas em decorrência da definição interna do padrão corporativo ${ }^{8}$.

Quanto ao tipo de licitação, caso seja feita uma avaliação de software mediante a atribuição de pontuação para cada quesito estabelecido pela Administração, a licitação necessariamente deverá ser do tipo "técnica e preço".

Sem embargo, é possível a realização de licitação do tipo "menor preço" na situação em que o estudo técnico prévio constatar que diversos softwares atenderiam satisfatoriamente aos requisitos estabelecidos pela Administração sem que haja uma justificativa técnica preponderante para a contratação. Assim, o princípio da economicidade aponta no sentido de buscar o menor custo, desde que atendida a qualificação técnica do software-licitante.

\section{III.b - DA PADRONIZAÇÃO PELO USO}

Podem ocorrer situações em que o uso massivo, prolongado ou vultosos investimentos feitos em um determinado programa justifiquem a utilização deste como padrão, levando à inexigibilidade de licitação nas contratações posteriores, sem que tenha sido elaborado um prévio estudo técnico.

Assim, o uso em massa de um determinado programa dentro e fora da Administração pode levar a uma situação de inviabilidade em virtude da necessidade de conhecimento prévio dos usuários no uso do referido programa.

Em outras situações, foram feitos vultosos investimentos em um determinado aplicativo, que alcançou um desenvolvimento peculiar dentro da própria Administração, podendo se falar em uma "quase-parceria" com o titular do software. Assim, a customização interna do programa levou a uma situação de inviabilidade, tornando-o o único a atender determinadas peculiaridades da Administração.

Nestas situações, a padronização não decorreu de um estudo técnico prévio, mas de uma situação de fato que gerou a inviabilidade de competição num procedimento licitatório.

Em relação ao que aqui chamamos de "padronização pelo uso", o TCU já

\footnotetext{
${ }^{8}$ Mesmo nesta hipótese será possível a realização de licitação quando o titular do programa possuir diversos canais de distribuição, como melhor veremos a seguir.
} 
decidira pela sua legitimidade em diversas ocasiões:

"as razões que conduziram à opção por sistemas operacionais da 'família Windows', o Ministério, em robusto trabalho (cf. volume 1), elenca: a observância do princípio da padronização (tais sistemas foram os adotados nas duas primeiras fases do Proinfo); a predominância marcante dos produtos MSWindows entre as organizações brasileiras, a familiaridade de diretores, professores e alunos das escolas públicas com o ambiente; a maior facilidade na obtenção de suporte técnico; a existência de grande numero de títulos de interesse educacional na plataforma Windows; entre outras..."9.

"a padronização pode ser considerada quando, existindo plataforma anterior em pleno uso, sua troca possa causar prejuízos que superem os ganhos advindos da nova contratação,..."

Sem embargo, no momento da contratação de um programa com fundamento em uma situação de "padronização pelo uso", é recomendada que seja elaborado um documento onde conste e esteja devidamente justificada a contratação nesta situação.

\section{IV - DA NECESSIDADE DE REVISÃO PERIÓDICA DA PADRONIZAÇÃO}

Mesmo que a contratação de um determinado programa esteja fundamentada em padronização, é recomendada a revisão periódica desta definição, de maneira a se verificar se permanecem as vantagens econômicas, técnicas e corporativas da padronização na dita tecnologia.

Como é sabido, o mundo da Tecnologia da Informação é caracterizado pela rápida inovação e evolução nos paradigmas tecnológicos. Uma tecnologia nova é sucedida por outra numa velocidade cada vez maior. Programas que outrora eram usados em larga escala são rapidamente substituídos por versões mais novas ou soluções tecnológicas de empresas concorrentes. O mercado oferece quase que instantaneamente soluções alternativas e mais eficazes, levando a uma disputa acirrada por consumidores. O ICQ ${ }^{11}$, por exemplo, foi o programa pioneiro de comunicação instantânea, tendo sua primeira versão lançada em 1997. Alcançou uma grande popularidade, mas sofreu uma forte concorrência de programas

\footnotetext{
${ }^{9}$ Acórdão 1713/2003 Plenário

${ }^{10}$ Acórdão no 740/2004 - Plenário

${ }^{11}$ A sigla é baseada na pronúncia das letras em inglês (I Seek You), em português, "eu procuro você".

${ }^{12}$ Acórdão 1521/2003 - Plenário

$13 \mathrm{Na}$ caracterização de preços excessivos deve ser levado em conta o disposto no parágrafo único do art. 21 da Lei no 8.884/94 que esclarece o seguinte:

"na caracterização da imposição de preços excessivos ou do aumento injustificado de preços, além de outras circunstâncias econômicas e mercadológicas relevantes, considerar-se -á:

I - o preço do produto ou serviço, ou sua elevação não justificada pelo comportamento do custo dos respectivos insumos, ou pela introdução de melhoria de qualidade. 59 Parecer SEAE, p.43, fls. 45 dos autos confidenciais. 39

II - o preço do produto anteriormente produzido, quando se tratar de sucedâneo resultante de alterações não substanciais.

- o preço de produtos e serviços similares, ou sua evolução, em mercados competitivos comparáveis.
} 
similares que vieram posteriormente como o Windows Live Messenger, Yahoo! Messenger e o Google Talk, que abocanharam grande parte dos usuários do serviço de comunicação instantânea.

Tendências futuras, como a adoção cada vez maior do software livre, virtualização, cloud computing, green IT, uso de tecnologia VoIP no lugar de serviços de telefonia, impactam os planos de negócios a longo prazo das organizações, seus programas e iniciativas. Assim, essas inovações podem assumir um papel estratégico porque dão um diferencial competitivo para aqueles que as adotam mais rapidamente.

O software livre, por exemplo, já vem sendo adotado em grande parte da Administração Pública e representa um salto em termos de economicidade e independência tecnológica.

Um ponto negativo da padronização é que cria uma situação de aprisionamento, ou seja, após a escolha de um determinado produto, a Administração fica à mercê da aquisição e atualização do software-padrão. Com o uso do software livre eliminase este lock in, pois o código-fonte do programa está disponível ao usuário, que poderá alterá-lo sem necessitar contratar novamente o desenvolvedor ou seu representante comercial. Ademais, propicia uma flexibilização no desenvolvimento, melhoria e integração de sistemas, obtenção da propriedade intelectual dos softwares, dentre outros.

Por conseguinte, a padronização não pode causar um engessamento da Administração na contratação de programas de computador. É vital a revisão das vantagens econômicas, técnicas e corporativas da padronização. O próprio estudo técnico prévio pode conter um prazo para que seja feita uma revisão futura ou revisões periódicas da padronização, de forma que a Administração esteja aberta a novas oportunidades e soluções tecnológicas mais econômicas ou eficazes. Na revisão, deve ser levado em conta, juntamente com as soluções proprietárias, o uso de software livre. As contratações serão feitas com base na relação custo-benefício do software livre ou software proprietário.

\section{V - DA EXCLUSIVIDADE DA REPRESENTAÇÃO COMERCIAL}

Mesmo que determinado programa seja definido como padrão, não fica impedida a licitação entre os canais de distribuição do programa. Ocorre que, no mais das vezes, o desenvolvedor estabelece um representante comercial exclusivo para a comercialização ou prestação de serviços relacionados ao software.

Com efeito, a decisão de estabelecimento de canal único ou canais restritos de comercialização é denominada "restrição vertical". As restrições verticais não podem ser analisadas de forma absoluta e condenadas a priori pois, apesar de estabelecerem uma redução nos canais de distribuição, podem representar um ganho na relação de concorrência inter-marcas e intra-marcas. Isso porque, quanto maior for a concorrência entre as marcas, tanto maior será a possibilidade dos efeitos positivos a favor da concorrência e da eficiência compensarem quaisquer efeitos anticoncorrenciais decorrentes das restrições verticais.

Em princípio, vige a liberdade dos produtores em escolher os seus parceiros e 
a legitimidade das empresas para adotar modelo comercial próprio. Com efeito, originariamente, a Administração só poderia contratar diretamente com o detentor da titularidade autoral, caso não existissem distribuidores, sendo inexigível, a priori, a licitação. Poderá, entretanto, o titular do software indicar um ou vários representantes comerciais. No primeiro caso, a contratação dar-se-ia por inexigibilidade, desde que a exclusividade esteja comprovada por documento hábil; no segundo, a licitação é indeclinável, havendo a possibilidade de licenciamento com mais de um representante comercial.

Neste sentido o TCU entendeu ser juridicamente possível que o desenvolvedor eleja representante exclusivo para comercialização de softwares com a Administração Pública Federal: ${ }^{12}$

“42.É certo que, naquela época, a TBA era o único LAR credenciado pela Microsoft para atuar no Distrito Federal, local que concentra grande parte das contratações da Administração Pública Federal. Muito embora essa fosse uma situação criticável no âmbito do Direito Administrativo e, muito mais, no âmbito do Direito Econômico, era uma realidade e poderia justificar a inexigibilidade de licitação para a contratação de licenças de software via Select. Além disso, esse contrato corporativo, em vista do volume de software pactuado, oferecia supostas vantagens em preço e outras facilidades.

43. Considerando o acima exposto, o TCU ao avaliar o contrato Select da ECT, em 1999, não se manifestou conclusivamente pela irregularidade da contratação de licença de software sem licitação, de maneira que, decorridos vários anos, não vislumbro razoabilidade numa manifestação nessa linha. Não obstante, este Tribunal não pode deixar de, nos processos em forem apreciados os contratos celebrados com os diversos órgãos e entidades da Administração, avaliar a regularidade dos preços contratados".

Trata-se, assim, de um problema de política comercial do desenvolvedor e seus canais de distribuição, por um lado, e de eventual abuso de posição dominante e restrição vertical, por outro, e que compete ao CADE - Conselho Administrativo de Defesa Econômica, averiguar, eis que se trata de prejuízo à concorrência e de infração contra a ordem econômica.

Sem embargo, deve ser levado em conta que a exclusividade determinada não poderá prejudicar o princípio da economicidade na contratação com a Administração, com a imposição de preços excessivos ou o aumento injustificado de preços ${ }^{13}$. Tal fato ocorreria se a exclusividade permitisse que a firma pudesse perceber lucros extraordinários. Restaria caracterizado, nesta hipótese, abuso de poder econômico e lesão contratual em detrimento da Administração, o que poderia levar, inclusive, à necessidade de denúncia ao CADE Conselho Administrativo de Defesa Econômica e pleito judicial de reequilíbrio das estipulações contratuais.

\section{VI - CONCLUS̃̃O}

A contratação do licenciamento de uso de softwares deve seguir o 
preceituado no art. 45, $\S 4^{\circ}$, da Lei n. 8.66693, adotando-se obrigatoriamente o tipo de licitação "técnica e preço", salvo em caso de padronização, onde é juridicamente possível a contratação adotando-se outros tipos de licitação, ou até diretamente, por inexigibilidade.

Existem inúmeras vantagens na padronização da contratação de softwares, mormente o ganho em economia de escala, compatibilidade de especificações técnicas e de desempenho, manutenção da garantia técnica, continuidade nos investimentos já realizados, etc.

Para que seja fundamentada a decisão de padronização em uma determinada tecnologia, é necessária a realização de um prévio estudo técnico, com teste de software se possível, para verificar, dentre as soluções existentes no mercado, quais atendem satisfatoriamente à demanda da Administração.

Sem embargo, é legitima a contratação de um determinado software em virtude de "padronização pelo uso", decorrente do uso massivo, prolongado ou de vultosos investimentos já realizados, sendo recomendada, nesta hipótese, a elaboração de um documento onde conste e esteja devidamente justificada a contratação nesta situação.

Por outro lado, a padronização não pode causar um engessamento da Administração na contratação de programas de computador. É vital a revisão das vantagens econômicas, técnicas e corporativas da padronização. O próprio estudo técnico prévio pode conter um prazo para que seja feita revisão futura ou revisões periódicas da padronização, de forma que a Administração esteja aberta a novas oportunidades e soluções tecnológicas mais econômicas ou eficazes. Nesta revisão, deve ser levado em conta especialmente o uso do software livre, juntamente com as soluções proprietárias.

O fato de um programa ser definido como padrão não impede que seja feita licitação entre os seus canais de distribuição. Entretanto, é legítimo que o titular de programa de computador estipule um representante comercial exclusivo para a comercialização ou prestação de serviços relacionados ao software, desde que não prejudique a economicidade na contratação, com imposição de preços excessivos ou o aumento injustificado de preços.

\section{VII - BIBLIOGRAFIA}

- Aristóteles. Ética a Nicômaco - Livro V - Coleção “Os pensadores” pág. 81 a 98. Ed. Nova Cultural. 1987

- Ascensão, José de Oliveira. Direito de Autor e Direitos Conexos”. Coimbra Editora Limitada: Lisboa, 1992.

- Bain J. S. (1956) Barriers to New Comepetition Cambridge, Mass.: Harvard University Press.

- Barbosa, Denis Borges. Uma Introdução à Propriedade Intelectual. Rio de Janeiro: Editora Lumen Júris 2003. 
- Di Pietro, Maria Sylvia Zanella. Direito Administrativo. $21^{\mathrm{a}}$ ed., São Paulo: Atlas, 2008.

- Fernandes, Jorge Ulisses Jacoby. Vade-mécum de Licitações e Contratos. $3^{\circ}$ Edição. 2008. Editora Fórum

- Gasparini, Diógenes. Direito Administrativo. 13ª ed. São Paulo: Saraiva, 2008.

- Gomes, Orlando. Contratos. Atualização por Humberto Teodoro Jr. $24^{\circ}$ edição. Rio de Janeiro. 2001. Editora Forense

- Justen Filho, Marçal. Comentários à Lei de Licitações e Contratos Administrativos. $12^{\circ}$ edição. 2008. Editoria Dialética

- Justen Filho, Marçal. Curso de Direito Administrativo. 2005. $1^{\circ}$ Edição. Editora: Saraiva

- Katz, M. e Shapiro, C. "Antitrust in Software Markets", Progress and Freedom Foundation, September 1998., pág. 16.

- Meirelles, Hely Lopes. Direito Administrativo Brasileiro. $29^{\circ}$ Edição. 2004. Editora Revista dos Tribunais

- Pereira Júnior, Jessé Torres, Comentários à Lei das Licitações e Contratações da Administração Pública. $7^{\circ}$ Edição. 2007. Editora Renovar

- Villey, Michel - Filosofia do Direito: Definições e Fins do Direito. 1977 Editora Martins Fontes. 